\title{
Characterizing Vulnerability of Crop-Based Rural Systems to Climate Change and Variability: Agro-Ecology Specific Empirical Evidence from the Dabus Watershed, North-West Ethiopia
}

\author{
Paulos Asrat*, Belay Simane \\ College of Development Studies, Center for Environment and Development Studies, Addis Ababa University, \\ Addis Ababa, Ethiopia \\ Email: *paulosasrat63@gmail.com, simaneb@yahoo.com
}

How to cite this paper: Asrat, P. and Simane, B. (2017) Characterizing Vulnerability of Crop-Based Rural Systems to Climate Change and Variability: Agro-Ecology Specific Empirical Evidence from the Dabus Watershed, North-West Ethiopia. American Journal of Climate Change, 6, 643-667. https://doi.org/10.4236/ajcc.2017.64033

Received: October 1, 2017

Accepted: December 16, 2017

Published: December 19, 2017

Copyright $\odot 2017$ by authors and Scientific Research Publishing Inc. This work is licensed under the Creative Commons Attribution International License (CC BY 4.0).

http://creativecommons.org/licenses/by/4.0/

\begin{abstract}
Climate change is impacting climate sensitive rural livelihood systems. Exposure, sensitivity, and adaptive capacity of agricultural livelihoods to climate variability and change differ across agro-ecologies and these pose a challenge to climate resilient development strategy. This study assesses agro-ecology specific vulnerability of smallholder farmers to climate change and variability in the Dabus Watershed (North-west Ethiopia), based on a survey of 734 farm households complemented with focus group discussion and key informant interviews. Recognizing the physiographic and climatic diversity that exists across agro-ecologies in the study area, Livelihood Vulnerability Index (LVI) framed within the United Nations Intergovernmental Panel on Climate Change (IPCC) vulnerability framework (LVI-IPCC) is adapted to assess agro-ecology specific vulnerability in two local agro-ecologies, namely wet lowland and dry lowland. For each agro-ecology, exposure, sensitivity and adaptive capacity indices as well as LVI-IPCC vulnerability score was calculated. The result shows that the dry lowland agro-ecology has a relatively higher exposure and sensitivity to climate stresses with a comparatively limited adaptive capability. On the other hand, the wet lowland agro-ecology exhibits intermediate vulnerability with a relatively lower perceived exposure and higher adaptive capacity. Higher exposure relative to adaptive capacity resulted in a positive LVI-IPCC score in the dry lowland agro-ecology and positioned it in more vulnerable level than the wet lowland. A higher adaptive capacity relative to exposure unveils a negative LVI-IPCC score for the wet
\end{abstract}


lowland agro-ecology and positioned it in a moderate vulnerability category. In line with the findings, there is a need to set agro-ecology specific priorities for intervention that is most needed to cop up with the effects of climate variability and change in each agro-ecology. Climate risk exposure levels can be reduced through timely provision of climate specific information and early warning systems aimed at enhancing preparedness of farm households to extreme events. It is also crucial to expand availability of infrastructural facilities such as market, health services, and veterinary services so as to enhance adaptive capacity. Supporting alternative livelihood options and enhancing water harvesting practices for supplementary irrigation also call policy attention.

\section{Keywords}

Ethiopia, Climate Change, Exposure, Sensitivity, Adaptive Capacity, Vulnerability, Agro-Ecology

\section{Introduction}

Based on the predication made by Intergovernmental Panel on Climate Change (IPCC), the expected increase in global temperature in the next two decades is between $0.3^{\circ} \mathrm{C}$ and $0.7^{\circ} \mathrm{C}$ [1]. Based on this prediction, [2] [3] revealed an increase of temperature between $0.3^{\circ} \mathrm{C}-4.8^{\circ} \mathrm{C}$ by the end of the $21^{\text {st }}$ century depending on emission scenarios. The increase in temperature is also evidenced by an increase in frequency of extreme events such as drought, floods and emergence of different crop and animal pests and diseases. The changes have also been manifested through increase in duration of hot days hot nights, and heat waves. These variability and change in climate have already made Africa most vulnerable owing to its high reliance on climate sensitive sector and low adaptive capacity [4] putting about 600 million Africans at risk of water stress, extensive floods, drought, and famine. Sub-Saharan Africa will be the most vulnerable part as these risks will cause a reported decline of $10-20$ percent in crop yields by 2050, which will also lead to a significant decline in crop revenue [1] [2] [3] [4] [5].

According to [1], vulnerability to climate change is the extent to which a system or community is prone or at risk and unable to deal with the negative effects of climate change and variability. Vulnerability is not a static concept, it varies in space and time; and its level also depends on the rate of change of climate and the extent to which the system is exposed, its sensitivity and adaptive capacity. Based on the same source, sensitivity refers to the extent to which a system is either negatively or positively, directly or indirectly affected by climate change and variability. Adaptive capacity on the other hand is the ability of a system to reduce/moderate the potential effects of climate change and variability by either taking advantages of existing opportunities or undertaking measures to deal with its consequences. 
As part of Sub-Saharan Africa, the livelihood of about 85 percent of the labor force in Ethiopia is dependent on the climate sensitive sector, agriculture and this sector also contributes 40 percent of the countries' GDP [6] [7] [8]. In line with this Von Braun [9], estimated that a 10 percent decrease in main season rainfall from the long-term average causes a 4.4 percent decrease in the national food production. Consequently, if this situation left unmanaged, it may end up in a decline of the country's GDP growth projected in the range of 0.5 to 2.5 percent annually [10] [11]. Generally, the heavy reliance on the climate sensitive sector; unsustainable pattern of land use practices; and lack of necessary capital to invest in adaptation options exacerbate the consequences of climate change in Ethiopia [12] [13].

There are some studies which assessed vulnerability to extreme climate events in Ethiopia. Using national data, [14] have employed "vulnerability as expected poverty" approach to develop an index that determines the vulnerability levels of stallholder farmers to climate extremes. On the other hand, Simane et al. [15] have used Livelihood Vulnerability Index (LVI) and LVI-IPCC framework to determine smallholder farmers' vulnerability to climate change impacts in a high land agro-ecosystems. However, to the best of our knowledge, no previous agro-ecology specific studies on vulnerability to climate change impacts have been conducted in the country in general and in lowland agro-ecologies in particular.

Considerable diversity is prevailing in Ethiopia in terms of agro-ecology, socio-economic set up, climate change and variability, environmental conditions, agricultural production systems, water resources and biodiversity [14] [15]. Given this diversity, aggregate assessment cannot capture the complexity of vulnerability at agro-ecology level and may lead to blanket recommendations [15]. The present study, therefore, adds to the vulnerability literature and contributes to the building of agro-ecology specific resilience in Ethiopia by assessing agro-ecology specific vulnerability to climate change and variability. The results of the study are indispensable to ensure better targeting of agro-ecology specific adaptation measures and developmental interventions.

\section{Methodology}

\subsection{Study Area}

Dabus sub basin has an area of $21,030 \mathrm{~km}^{2}$. The altitude in the sub basin ranges between 485 and 3150 masl. The sub basin has an annual rainfall ranging between $970 \mathrm{~mm}$ and $1985 \mathrm{~mm}$. The annual maximum and minimum temperature in the sub basin varies between $20^{\circ} \mathrm{C}-35^{\circ} \mathrm{C}$ and $8.5^{\circ} \mathrm{C}-20^{\circ} \mathrm{C}$, respectively. The sub-basin is characterized by hot to warm moist and sub humid lowlands (Figure 1). Considerable part of the sub basin is cultivated and is characterized by Maize-sorghum and maize-sorghum-perennial complex. The total population of the study area is 412,754 .

The study area is among the most vulnerable lowland agro-ecologies to climate variability and change in Ethiopia. Climate variability and change poses a 

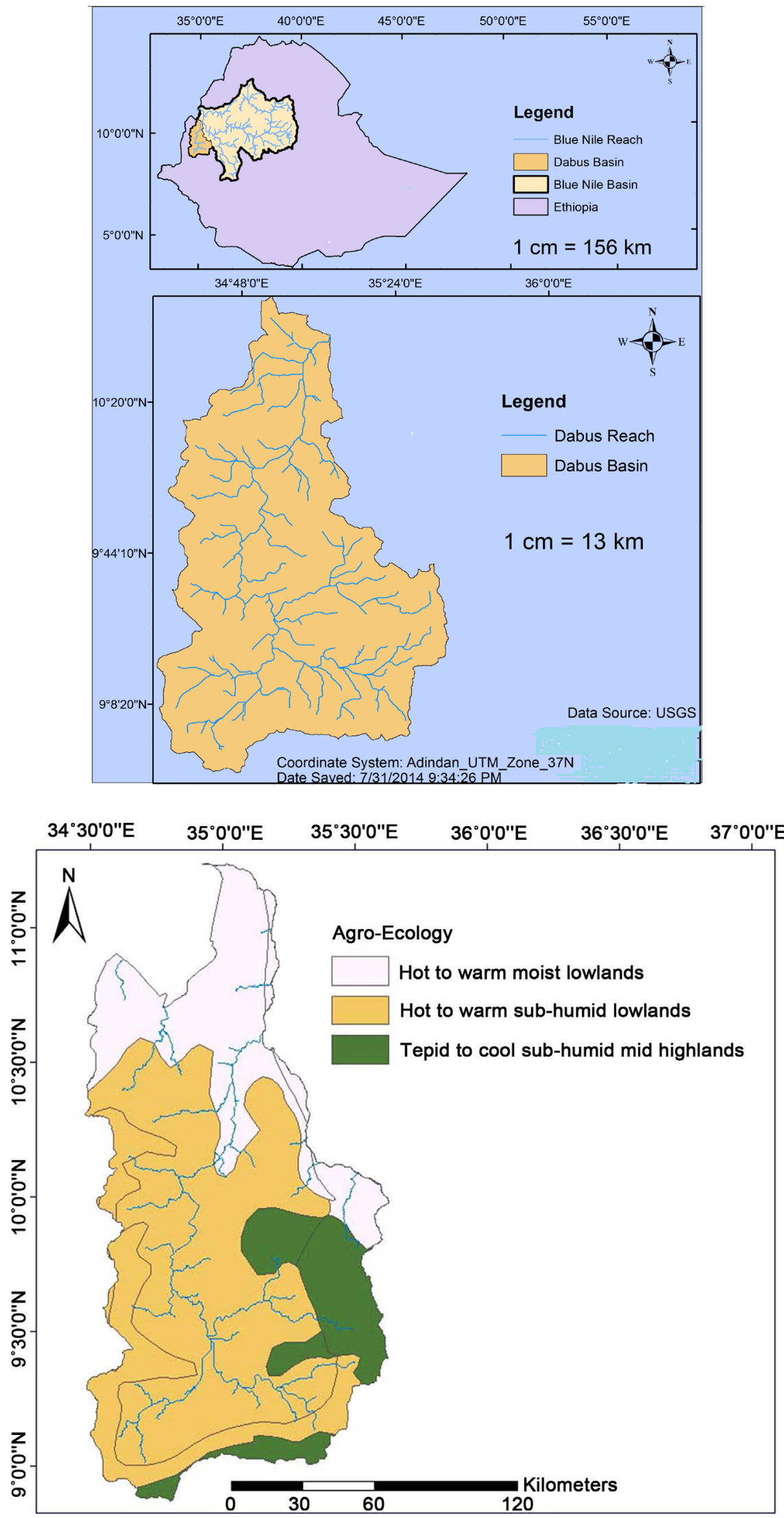

Figure 1. Map of the research area and agro-ecological zones. 
huge threat to farmers in the area, the stressful problems being overwhelming reliance on small-scale agriculture, land degradation and water shortages. A preliminary assessment made in the specific sites of this study shows that the level of climate change impacts varies across the agro-ecologies but has commonly caused multiple impacts through direct and indirect processes affecting a wide array of ecosystem functions and services. Among its direct effects is the loss of fertile soils, a decline in productivity and rural income and hence possess a challenge on the adaptive capacity of the smallholder farmers to climate hazards.

\subsection{Data Source and Sampling Procedure}

A cross-sectional survey was conducted from August to October, 2016 engaging 734 farm households in two agro-ecologies of the Dabus sub-basin. Accordingly 371 and 363 households were drawn from the wet lowland (wet LL) and dry lowland (dry LL) agro-ecologies, respectively. The sampling procedure involved four stages. In the first stage, the two agro-ecologies were purposively drawn. In the second stage two Woredas were randomly selected from each agro-ecology and this makes the total number of Woredas included in the sample four. In the third stage, three rural kebeles (the smallest administrative unit) were randomly drawn from each of the Woredas and hence 12 rural kebeles were included in the sample. Finally, a total of 734 farm households were sampled from the rural kebeles on the basis of probability proportionate to size sampling procedure.

A survey questionnaire was designed in such a way that it addresses issues related to the 12 major components (profiles) that include natural resource; natural disaster; climate change and variability; land use system and sustainability; agriculture; income/wealth; technology; infrastructure; livelihood; knowledge/skill; socio-demographic; and social network. Corresponding to these major components, the questionnaire also addresses 37 indicators (sub-components). The 12 major components along with the associated 37 indicators are portrayed in $\mathrm{Ta}$ ble 1. The data from household survey were also triangulated with focus group discussions, key informant interviews, field observations and secondary data from Central Statistics Agency of Ethiopia, regional office. Moreover, the climate data that is used to assess exposure level were obtained from proxy stations of the national meteorological service agency.

\subsection{Approaches to Measuring Vulnerability}

Vulnerability can be analyzed either on the basis of risk hazard or social constructive frameworks [15] [16]. The risk hazard model tends to assess several possible impacts of a single climatic event whereas the social constructive model tends to emphasis the several possible causes of a single climatic event. Application of the risk hazard model generally emphasis exposure and sensitivity to environmental stressors and operates from the hazard to the impact [17].

In the risk hazard approach, several methods have been developed for aggregating indicators and computing an index and key among them are the gap method and the weighting method. The gap method assesses vulnerability based on 
Table 1. Major components and indicators.

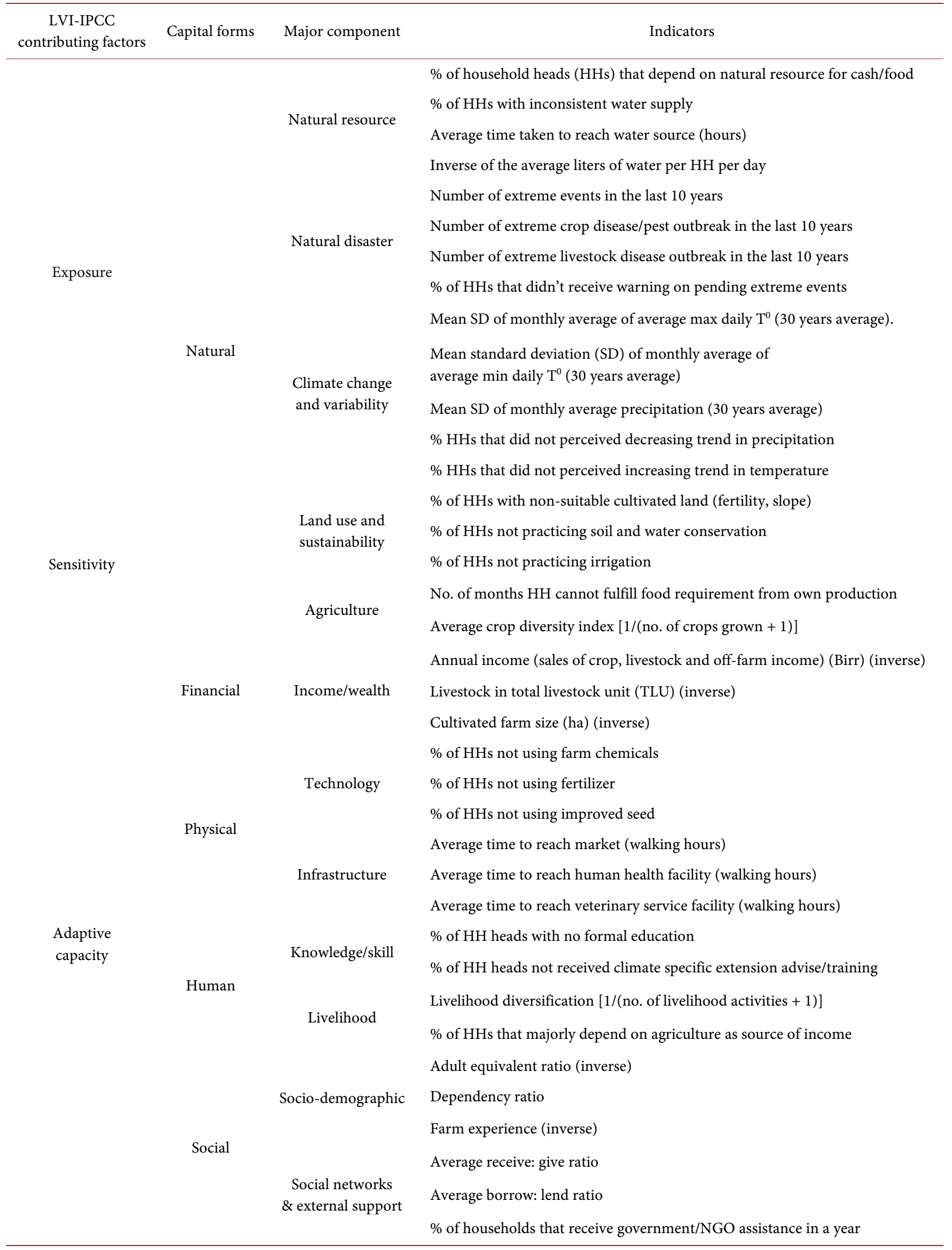


the deviation of stallholder farmers' current condition from predetermined level in the absence of climate change and variability. The weighting method on the other hand is based on valuing the importance of each indicator in terms of contributing to making smallholder farmers vulnerable to climate change and variability [15] [18]. In another perspective, econometric methods and indicators approaches can be employed to measure vulnerability to climate change and variability [14]. The indicator approach involves selection of indicators that a researcher considers to account for vulnerability. However, the weakness of this approach is that there could be some level of subjectivity in choosing the various indicators. Since the focus of the present study is on valuing the importance of various indicators, it opts for the balanced weighting approach to compute the LVI.

"Vulnerability as expected poverty" approach was used by [14] to measure farmers' vulnerability to climatic extremes with a particular reference to drought and floods. They estimated the probability that a given set of shocks will move a household's consumption below consumption poverty line or force the consumption level to remain below a given minimum if the consumption is already below this level. However, this approach captures vulnerability as expected poverty (the tendency to be poor in the future as a result of climate extremes) and hence only measures future and not current vulnerability. An aggregate vulnerability index was developed by [19] to determine the level of vulnerability of the farming sector to climate change and variability by selecting and aggregating a number of variables that together serve as a proxy for vulnerability. Nevertheless, development of the aggregate index requires secondary data on both macroeconomic (such as agricultural GDP) and microeconomic (household level farm income) indicators, which is not readily available at agro-ecology level.

The present study adopted the indicator (composite index) approach in measuring the vulnerability of smallholder farmers to climate change and variability based on the livelihood vulnerability index (LVI) developed by [18]. This approach uses household level primary data (except data for precipitation and temperature) and takes into account several variables to capture the level of exposure to climate hazards, adaptive capacity and sensititvity to climate change impacts. Unlike other techniques, the LVI approach not only addresses future susceptibility but also the current vulnerability which is useful for current adaptation planning. Therefore, LVI framed within the Livelihood Vulnerability Index-Intergovernmental Panel for Climate Change (LVI-IPCC) is contextualized and used to assess agro-ecology specific smallholder farmers' vulnerability to climate change and variability in the study area.

\section{Livelihood Vulnerability Index}

Since indicators are measured on a different scale, they have to be first standardized as an index. The equation used for this standardization is adapted from that used in the Human Development Index [20] as also used in [18] to calculate Livelihood Vulnerability Index in Mozambique and in [15] for calculation of 
Livelihood Vulnerability Index to assess vulnerability of smallholder farmers in the highland agro-ecosystems. The current vulnerability analysis involve calculation of a balanced weighted average LVI (composite index), in which each major component contributes equally to the overall index. Accordingly, first the raw data is transformed into appropriate measurement units such as percentage, ratio and indices and then the indicators measured in different scale are standardized (Equation (1)).

$$
l v i=\frac{S_{a}-S_{\min }}{S_{\text {max }}-S_{\text {min }}}
$$

where $I_{v i}$ is the standardized value for the indicator, $S_{a}$ is the observed (average) sub-component indicator for agro-ecology a, and $S_{\min }$ and $S_{\max }$ are the minimum and maximum values, respectively for the indicator across the two agro-ecologies. Then, the sub-component indicators are averaged (Equation (2)) to obtain the index of each major component.

$$
M_{a}=\frac{\sum l v i}{N}
$$

where $M_{a}$ is one of the 12 major components for agro-ecology a; index $l v i$ represents the sub components indexed by $i$, that make up each major component and " $N$ " is the number of sub-components in each major component. Equation (3) combines the weighted averages of all the major components to generate the LVI score. The number of indicators of which it is compressed to determines the weights of each major component $\left(W M_{i}\right)$. Values for each of the 12 major components for an agro-ecology are calculated and averaged (Equation (3)) to obtain the agro-ecology level $L V I$ :

$$
L V I_{a}=\frac{\sum_{p=1}^{12} W M_{i} M_{a i}}{\sum_{p=1}^{12} W M_{a i}}
$$

where, $L V I_{a}$ is the Livelihood Vulnerability Index for agro-ecology a. Based on the above three equations, Hahn et al. (2009) calculated the major components of LVI based on the LVI-IPCC vulnerability categorization in to Exposure (E), Sensitivity (S) and Adaptation (A) as stated in Equation (4):

$$
C F_{a}=\frac{\sum_{p=1}^{f} W M_{i} M_{a i}}{\sum_{p=1}^{f} W M_{a i}}
$$

where, $C F_{a}$ is the LVI-IPCC defined contributing factors for agro-ecology a, $M_{a i}$ are the major components for the agro-ecology a, indexed by $i, W M_{i}$, the weights of each major components, $f$ is the number of the profiles associated contributing factors and $p$ is indexed to the profiles associated with the CF. Finally, the LVI-IPCC is computed using Equation (5).

$$
\text { LVI-IPCC }{ }_{a}=\left(E_{a}-A_{a}\right) * S_{a}
$$


where, $L V I-I P C C_{a}$ is the LVI for agro-ecology a expressed using the IPCC vulnerability framework, $E_{a}$ is the calculated exposure score for agro-ecology a, $A_{a}$ is the calculated adaptive capacity score for agro-ecology a and $S_{a}$ is the calculated sensitivity score for agro-ecology a. The LVI-IPCC is scaled from -1 (least vulnerable) to 1 (most vulnerable) and is best understood as an estimate of the relative vulnerability compared to populations in the agro-ecology.

\section{Results and Discussion}

\subsection{Vulnerability Index Components and Sub-Components}

Livelihood vulnerability has economic, political, social, demographic and institutional dimensions [4] [21]. As a result, practical assessment of livelihood vulnerability is very complicated and their applicability is also context specific. Therefore, the present research only focuses on major factors (major components and sub-components) that are related to different livelihood assets at household level. The major components and the sub-components used to construct the LVI were selected based on primary data generated through household survey, focus groups discussion, key informant interview, expert opinion, and field observation.

The study adopted the risk hazard model to assess agro-ecologically classified vulnerability of smallholder farmers to climate variability and change. It valued the importance of various indicators and applied the balanced weighting approach to compute the LVI. Accordingly, the vulnerability index is derived for the two agro-ecologies of the study area based on the IPCC definition of vulnerability to climatic impacts making use of 12 major components aligned to the three vulnerability contributing factors (exposure, sensitivity and adaptive capacity). The exposure category consists of three major components namely natural resource, natural disaster and climate variability and change. In the adaptive capacity category, seven major components including finance, technology, infrastructure, livelihood, socio-demographic, social net-work and knowledge are considered. Similarly, land use system and sustainability as well as agriculture are included in the sensitivity category. Parallel to this, each major component is made up of several indicators (37 in total), which are standardized as index since each of them is measured on a different scale.

\subsection{LVI-IPCC Contributing Factors and Indexed Components}

This section describes the LVI-IPCC contributing factors, the major components and the indicators along with comparing the calculated indices between the two agro-ecologies of the study area. The indices for the major components, sub-components and contributing factors are relative values and hence compared between the two agro-ecologies within the sample only.

\subsubsection{Exposure}

The exposure factor consists of three major components that fall in the natural 
capital category. Theses major components are climate change and variability; natural resource; and natural disaster, which in turn comprise 13 sub-components or indicators.

\section{1) Natural Resource Component}

This major component is composed of four indicators. In terms of access to water, the dry lowland agro-ecology has the highest percentage (63\%) of households without consistent water supply compared to 30 percent for the wet lowland. The average time taken to reach a nearest water source is higher in the dry lowland agro-ecology (about an hour) compared to 0.5 hour in the wet lowland. As water is usually sourced by women and young girls, distant water sources imply mounted pressure on female household members. In terms of keeping water stock for future use, households in the wet lowland agro-ecology are better as reveled by the calculated inverse liters of water stored per household per day, which 0.018 for the wet lowland agro-ecology compared to 0.042 for the dry lowland.

Comparatively more households in the dry lowland agro-ecology (35\%) depend on forest products as food and cash source compared to 12 percent in the wet lowland. Exposure varies positively with the level of contribution of natural resources to livelihoods and this is in line with Bankoff et al. (2004), who reported a strong association between dependence on natural capital and vulnerability to climate change risks. Moreover, large dependence on the natural resource may divert farmers' attention away from the regular farm activities and enhance their exposure to climate change induced risks. Therefore, considering the four indicators, the calculated Vulnerability Index for the natural resource component shows that the dry lowland agro-ecology is more vulnerable (with a score of 0.219) compared to the wet lowland (with a score of 0.152) (Table 3).

\section{2) Natural disaster component}

This major component is composed of four indicators. Intermittent drought is the typical extreme climate event that induces vulnerability of the farming community in both agro-ecologies. In this regard, farm households in the dry lowland agro-ecology faced more frequent challenge $(7$ times) in the past 10 years compared to those in the wet lowland agro-ecology ( 3 times). In terms of major crop disease/pest outbreaks, households in the dry lowland agro-ecology faced the challenge 4 times in the past 10 years compared to 3 times in the wet lowland agro-ecology. The other challenge is major livestock production risk (disease), which have been prevalent 4 times in both agro-ecologies in the last 10 years.

In both agro-ecologies, about 76 percent of the respondents did not receive any warning about pending extreme events that could have helped them adequately respond and hence this increases their exposure risk to natural disaster. Disaggregating this proportion into the respective agro-ecologies entails lack of information about extreme events is more prevalent in the dry lowland agro-ecology where 88 percent of the respondents did not receive any warning compared to 64 percent in the wet lowland. Considering the four indicators, the 
Vulnerability Index for the natural disaster major component is higher for the dry lowland agro-ecology (0.324) as compared to the wet lowland agro-ecology (0.186) (Table 3).

\section{3) Climate change and variability component}

Farmers' perception of over time changes in precipitation and temperature along with climate data are the indicators used in this major component. This is line with previous studies [14] [15] [22] [23], which indicated that elements of the natural capital (such as temperature and precipitation) are important determinants of smallholder-farmers' exposure to climate risks. In the present study, about 78 percent of the respondents perceived that temperature has increased over the last 20 - 30 years, with a slightly higher perception of increasing temperatures in the wet lowland agro-ecology (84 percent) compared to 72 percent in the dry lowland. This is consistent with the metrological data that witnessed the wet lowland agro-ecology has experienced more variable precipitation and variation in both maximum and minimum daily temperature (Table 2). The meteorological temperature records in the study area have shown linearly increasing trends in average monthly maximum temperature since 1986 on an average of $0.4^{\circ} \mathrm{C}$ per decade.

With regard to precipitation, a decreasing trend is perceived by $64 \%$ of the respondents. This perceived change is different between the two agro-ecologies with relatively more perception of decreasing precipitation in the wet lowland agro-ecology (68\%) compared to 60 percent in the dry lowland. The changes in precipitation are apparently accompanied by late on set, early exit (terminal moisture stress) and prolonged rainfall in both agro-ecologies. The difference in perception concerning the trends of temperature and precipitation is plausible given the spatial and temporal variability of these climate variables across the two agro-ecologies.

But these changes in precipitation are little supported by measurements as most of them show no change or small change only. Shortfall of farmers perception with measurements may be attributed to the fact that increasing temperature with steady precipitation level may cause water stress for agricultural activities and hence cause farmers to believe that perception is decreasing overtime. This finding is in line with [15] who reported farmer perception of a precipitation shortfall with objective measures reflecting a climatic signal of increasing water stress when steady precipitation is associated with rising temperature.

Considering farmers' perception and substantiating it with objective records, the Vulnerability Index for the climate change and variability component is

Table 2. Precipitation and monthly average temperature.

\begin{tabular}{cccccc}
\hline \multirow{2}{*}{ Agro-ecology } & Altitude (masl) & Area (\%) & \multicolumn{2}{c}{$\mathrm{T}^{0}\left({ }^{\circ} \mathrm{C}\right)$} & Annual precipitation (mm) \\
\cline { 4 - 5 } & & & Min & Max & A \\
Wet lowland (LL) & $900-1500$ & 50.8 & 18 & 31 & $1200-1600$ \\
Dry lowland (LL) & $589-900$ & 42.2 & 18 & 35 & $970-1200$ \\
\hline
\end{tabular}


higher for the wet lowland agro-ecology (0.379) compared to the corresponding index for the dry lowland (0.331) (Table 3). As the calculated indices for climate change and variability major component in both agro-ecologies are positive, it is obvious that the main livelihood source (agriculture), which is dependent on climate variables, is highly exposed to climate risks.

On the basis of the three major components and the corresponding indicators, the exposure assessment reveals high score (0.291) for the dry low land agro-ecology as compared to (0.239) for the wet lowland justifying high exposure level of the dry lowland to the risk of climate change and variability (Table 3). Although the exposure score for the wet lowland agro-ecology is comparatively low, it is still in the high vulnerability range implying that agricultural production system in both agro-ecologies is at risk.

\subsubsection{Sensitivity}

The sensitivity contributing factor constitutes two major components that fall in the natural capital category; namely agriculture and land use and sustainability components, which again consist of five indicators.

\section{1) Land use and sustainability component}

Land degradation problems are prevalent in both agro-ecologies with varying degree of intensity owing to extensification, incursion into fragile lands, lack of/unsustainable land management practices and cultivation of non-suitable land. In this regard about 44 percent of the respondents in the wet lowland agro-ecology reported owned non-suitable cultivated land compared to 38 percent in the dry lowland. In response to these, farmers used different soil fertility

Table 3. Exposure LVI along with indexed major and sub-compeonts.

\begin{tabular}{|c|c|c|c|c|c|}
\hline Sub-component (indicators) & Wet LL & Dry LL & $\begin{array}{l}\text { Major component } \\
\quad \text { (profile) }\end{array}$ & Wet LL & Dry LL \\
\hline$\%$ of $\mathrm{HHs}$ that depend natural resource for cash/food & 0.146 & 0.306 & \multirow{4}{*}{ Natural resource } & \multirow{3}{*}{0.152} & \multirow{3}{*}{0.219} \\
\hline$\%$ of HHs with inconsistent water supply & 0.269 & 0.431 & & & \\
\hline Average time taken to reach water source (hours) & 0.175 & 0.098 & & & \\
\hline Number of extreme events in the last 10 years & 0.208 & 0.279 & & \multirow{4}{*}{0.186} & \multirow{4}{*}{0.324} \\
\hline Number of extreme crop disease/pest outbreak (last 10 years) & 0.130 & 0.240 & \multirow{2}{*}{ Natural disaster } & & \\
\hline Number of extreme livestock disease outbreak (last 10 years & 0.149 & 0.289 & & & \\
\hline$\%$ of HHs not receive warning on pending extreme events & 0.257 & 0.488 & \multirow{6}{*}{$\begin{array}{l}\text { Climate change } \\
\text { and variability }\end{array}$} & & \\
\hline$\% \mathrm{HHs}$ that don't perceived decreasing trend in precipitation & 0.344 & 0.286 & & \multirow{4}{*}{0.379} & \multirow{4}{*}{0.331} \\
\hline Mean SD of monthly average precipitation (30 years average) & 0.369 & 0.296 & & & \\
\hline $\begin{array}{l}\text { Mean standard deviation of monthly average of average } \\
\text { maximum daily temperature ( } 30 \text { years average). }\end{array}$ & 0.324 & 0.298 & & & \\
\hline $\begin{array}{l}\text { Mean standard deviation of monthly average of } \\
\text { average minimum daily temperature since ( } 30 \text { years average) }\end{array}$ & 0.441 & 0.386 & & & \\
\hline Exposure LVI & & & & 0.239 & 0.291 \\
\hline
\end{tabular}


management practices that include physical soil conservation measures and agronomic practices. Physical soil conservation measures are non-scale neutral and their application mostly requires larger plot size. However population pressure in the wet lowland agro-ecology poses a dwindling farm size per household and challenges application and economic feasibility of physical soil conservation measures implying that land fragmentation further induces vulnerability of smallholder agriculture to climate risks. Nevertheless, more use of the physical measures is reported in the wet lowland agro-ecology $(52.4 \%)$ compared to the dry lowland (33.6\%).

Famers also use non-physical soil conservation measures as a substitute or as a complement to physical soil conservation measures. The none physical measures largely constitute different agronomic practices, which are scale neutral and can be indiscriminately applied to both small and large land plots without land shrinking effect. These measures are practiced by 75 percent and 44 percent of the respondents in the wet lowland and dry lowland agro-ecologies, respectively. The two agro-ecologies have shown statistically significant variation in terms of use of both types of the soil conservation measures. The comparatively less use of both types of soil conservation measures in the dry lowland agro-ecology contributed to increased sensitivity of farm households to climate change and variability risks in this agro-ecology.

Dependence on rain-fed farming is the major feature of agricultural livelihood in both agro-ecologies. However, scattered traditional irrigation practices are witnessed among farm households in both agro-ecologies depending on land suitability, experience and water access. In this regard about 13 percent and 7 percent of respondents in the wet lowland and dry lowland agro-ecologies, respectively practice traditional irrigation. In this regard, less use of irrigation is positively associated to sensitivity to climate change risks and hence farm households in the dry lowland agro-ecology are more sensitive owing to their comparatively less use of the practice. Considering the three indicators, the Vulnerability Index for land use and sustainability component is higher for the dry lowland agro-ecology (0.366) compared to the corresponding index for the wet lowland agro-ecology (0.328) (Table 4).

Table 4. Sensitivty LVI and corosponding major and sub-compeonts.

\begin{tabular}{|c|c|c|c|c|c|}
\hline Sub-component (indicators) & Wet LL & Dry LL & Major component (profile) & Wet LL & Dry LL \\
\hline$\%$ of HHs with non-suitable cultivated land (fertility, slope) & 0.396 & 0.226 & & & \\
\hline$\%$ of $\mathrm{HHs}$ that do not practice any soil \& water conservation & 0.124 & 0.286 & Land use and sustainability & 0.328 & 0.366 \\
\hline$\%$ of $\mathrm{HHs}$ not practicing irrigation & 0.464 & 0.586 & & & \\
\hline Number of months a HH cannot fulfill food from own production & 0.136 & 0.238 & \multirow[b]{2}{*}{ Agriculture } & \multirow[b]{2}{*}{0.152} & \multirow[b]{2}{*}{0.244} \\
\hline Average crop diversity index [1/(no. of crops grown +1$)]$ & 0.167 & 0.250 & & & \\
\hline Sensitivity LVI & & & & 0.221 & 0.293 \\
\hline
\end{tabular}




\section{2) Agriculture}

This component is composed of two indicators and includes food self-sufficiency from own production and crop diversification. The two agro-ecologies are characterized by a crop dominant mixed crop-livestock system with some level of variation in the major crop types grown. The average number of months that a household unable to fulfill food requirement from own production in a year significantly varies between the two agro-ecologies. This is 4.8 months in the dry lowland agro-ecology compared to 2.5 months in the wet lowland, signifying more sensitivity of farm households in the dry lowland agro-ecology to climate stresses.

Crop diversification is prominent in both agro-ecologies aimed at fulfilling multiple household requirements and as a strategy of risk spreading; as well as dualistic nature of subsistence agriculture. However, crop diversification in the dry lowland agro-ecology is limited to few crop types compared to the wet lowland owing to less experience in the crop sector, environmental factors and comparative importance of the livestock sector. Accordingly, the calculated inverse crop diversification indices are 0.17 and 0.25 for the wet lowland and the dry lowland agro-ecologies, respectively.

When the two sub-components are averaged, the overall index for the agricultural component is slightly higher in dry lowland (0.244) compared to the wet lowland (0.152) implying that the wet lowland agro-ecology is positioned in relatively less vulnerable situation than the dry lowland in relation to this major component. Therefore, given the two major components and the corresponding indicators, the sensitivity assessment reveals high score for the dry low land agro-ecology (0.293) as compared to the wet lowland (0.221). This result justifies high sensitivity of the dry lowland to the risk of climate change and variability (Table 4).

\subsubsection{Adaptive Capacity}

The adaptive capacity category is composed of seven major components that fall in different capital forms (financial, physical, human and social). The major components are income/ wealth, livelihood, technology, infrastructure, knowledge/skill, socio-demographic, and social network. These major components again encompass 19 sub-components or indicators.

\section{1) Livelihood}

The livelihood major component is made up of two sub-components that include agricultural livelihood diversification and proportion of households that solely depend on agriculture. Excessive dependence on agriculture as source of food and cash is hypothesized to decrease the adaptive capacity of farm households to climate shocks. In this regard, more dependence on agriculture as a livelihood source is the major feature of the wet lowland agro-ecology, where involvement in non-farm/off-farm activities is only practiced by 24 percent of the respondents as compared to 56 percent in the dry lowland agro-ecology. The more a household engage in non-farm activities, the more the chance to cope 
with livelihood shocks that emanate from climate effects in agriculture in the short run. On other hand, more involvement on non-farm activities may divert attention away from the major source of livelihood and end up with enhanced vulnerability in the long run unless proceeds from non-farm activities are re-invested in agriculture. Therefore, the role of off-farm/non-farm activities for adaptation in agriculture may be indeterminate and depends on a household's decision on the proceeds from the activity.

The other indicator in the livelihood major component is agricultural livelihood diversification index. For households in the wet lowland agro-ecology, this index highly determined by crop and animal raring livelihood activities. The same index for the dry lowland agro-ecology is profoundly complemented and supplemented by off-farm/non-farm activities and use of forest products. Consequently, this difference in agricultural livelihood diversification between the two agro-ecologies is implied by an inverse index of 0.124 for the dry lowland agro-ecology compared to 0.112 for the wet lowland. Therefore, when the sub-components are aggregated, the calculated indexes for the livelihood competent are 0.134 and 0.145 for the wet lowland and the dry lowland agro-ecologies, respectively (Table 5).

Table 5. Adaptive capacity and indexed major and sub-compeonts.

\begin{tabular}{|c|c|c|c|c|c|}
\hline Sub-component (indicators) & Wet LL & Dry LL & Major component (profile) & Wet LL & Dry LL \\
\hline $\begin{array}{l}\text { Annual income } \\
\text { (crop, livestock, off-farm) (inverse) }\end{array}$ & 0.023 & 0.023 & \multirow{3}{*}{ Income/wealth } & \multirow{3}{*}{0.187} & \multirow{3}{*}{0.146} \\
\hline Livestock (TLU) (inverse) & 0.034 & 0.042 & & & \\
\hline Cultivated farm size (ha) (inverse) & 0.50 & 0.373 & & & \\
\hline$\%$ of households not using farm chemicals & 0.425 & 0.385 & \multirow{3}{*}{ Technology } & \multirow{3}{*}{0.448} & \multirow{3}{*}{0.342} \\
\hline$\%$ of households not using fertilizer & 0.415 & 0.246 & & & \\
\hline$\%$ of households not using improved seed & 0.505 & 0.396 & & & \\
\hline Average time to market & 0.219 & 0.168 & \multirow{3}{*}{ Infrastructure } & \multirow{3}{*}{0.286} & \multirow{3}{*}{0.183} \\
\hline Average time to human health facility & 0.284 & 0.178 & & & \\
\hline Average time to veterinary service facility & 0.354 & 0.204 & & & \\
\hline$\%$ of household heads with formal education & 0.268 & 0.164 & \multirow{2}{*}{ Knowledge/skill } & \multirow{2}{*}{0.278} & \multirow{2}{*}{0.194} \\
\hline$\%$ of $\mathrm{HH}$ heads received climate specific advise/training & 0.288 & 0.224 & & & \\
\hline $\begin{array}{l}\text { Agri. livelihood diversification } \\
{[1 /(\text { no. of agricultural livelihood activities }+1)]}\end{array}$ & 0.125 & 0.064 & \multirow[t]{3}{*}{ Livelihood } & \multirow[t]{2}{*}{0.134} & \multirow[t]{2}{*}{0.145} \\
\hline$\%$ of HHs more dependent on agri. as source of income & 0.142 & 0.225 & & & \\
\hline Adult equivalent (inverse) & 0.158 & 0.144 & & \multirow{3}{*}{0.234} & \multirow{3}{*}{0.223} \\
\hline Dependency ratio & 0.218 & 0.314 & \multirow[t]{2}{*}{ Socio-demographic } & & \\
\hline Farm experience (inverse) & 0.326 & 0.212 & & & \\
\hline Average receive: give ratio & 0.212 & 0.264 & \multirow{3}{*}{$\begin{array}{l}\text { Social networks and } \\
\text { external support }\end{array}$} & \multirow{3}{*}{0.272} & \multirow{3}{*}{0.203} \\
\hline Average borrow: lend ratio & 0.162 & 0.243 & & & \\
\hline$\%$ of $\mathrm{HHs}$ that receive Gov./NGO assistance in a year & 0.442 & 0.102 & & & \\
\hline \multicolumn{3}{|c|}{ Adaptive capacity LVI } & & 0.255 & 0.201 \\
\hline
\end{tabular}




\section{2) Income/wealth component}

The wealth profile is composed of three indicators, namely cultivated land size, livestock number (in TLU) and annual cash income from diversified sources (sale crop and livestock, and off-farm income). Comparing households in terms of total land holding size, the average for the wet lowland is 6.6 hectares, while it is 5.8 hectares for the dry lowland. In terms of cultivated land size, it is 1.68 hectares in the wet lowland agro-ecology while it is one hectare in the dry lowland, which is very close to the national average of 1.22 hectares [24]. However, vulnerability and adaptive capacity are more attributed to cultivated land size, utilization and productivity than the absolute land holding. Accordingly, vulnerability level inversely varies with cultivated land size owing to the opportunity it provides for crop diversification and implementation of soil conservation measures.

When the two agro-ecologies are compared in terms of annual income (crop enterprise, livestock and off-farm), households in the wet lowland on average generated Birr 4185 compared to Birr 4338 in the dry lowland. However, households in the wet lowland agro-ecology generated more income from crop enterprise while the major sources of annual income in the dry lowland are livestock sale and non-farm/off-farm activities. Similarly, the two agro-ecologies are compared in terms of livestock holding (on the basis of tropical livestock units). Accordingly, per capita livestock holding is higher in the dry lowland agro-ecology (5.57 TLU) compared to 3.37 TLU in the wet lowland and the difference is found to be statistically significant $(t=2.74 ; p<0.001)$. In line with this, the inverse average livestock unit (TLU) LVI score is 0.014 for the dry lowland agro-ecology compared to 0.112 for the wet lowland. Therefore, considering the indicators that constitute the income/wealth component, the dry lowland agro-ecology has less adaptive capacity with a calculated index of 0.146 compared to 0.187 for the wet lowland (Table 5).

\section{3) Technology component}

The two agro-ecologies are different in terms of the technology profile. The wet low land agro-ecology is better in terms of number of users of agricultural inputs attributed to better farming experience; access to credit and extension; and relatively favorable climatic for intensive crop production. However, in both agro-ecologies the use level is by far low compared to the recommended rate for most of the inputs. In the wet lowland agro-ecology, about 65 percent of the respondents reported use of fertilizer compared to 28 percent for the dry lowland. In the present study, use of chemical fertilizer is positively and significantly associated with farm experience whereas it is negatively correlated with livestock ownership ( $p$-value $=0.000$ ). This is in contrast with [15] who reported a positive relationship between fertilizer use and livestock holding. The negative relationship is due to complementarity between fertilizer and manure where large livestock holding induces more use of manure and less use of chemical fertilizer.

In terms of users of improved seed, it is higher for the wet lowland agro-ecology (44\%) compared to 18 percent in the dry lowland and the difference is statistically 
significant $(p<0.001)$. Parallel to this, comparatively large proportion of the respondents (68) reported use of different farm chemicals (mainly herbicides and insecticides) in the wet lowland agro-ecology compared to 34 percent in the dry lowland agro-ecology. Therefore, given the three indicators for the technology profile, the dry lowland agro-ecology has less adaptive capacity with an index of 0.342 compared to the wet lowland with an index of 0.448 (Table 5).

\section{4) Infrastructure component}

Three indicators are included in the infrastructure major component in reference to access to health facilities, veterinary services and market. Considering distance from doweling areas as an indicator, access to these infrastructural facilities slightly varies between the two agro-ecologies with a comparatively lower access in the dry lowland agro-ecology. On average, it takes 3 hours to reach the nearest health facility in the dry lowland agro-ecology compared to an hour in the case of the wet lowland. Less access to health facilities in the dry lowland agro-ecology is further justified by the prevalence of major human health risk in the area (malaria), which is reported by 43 percent of the respondents in the dry lowland agro-ecology compared to 24 percent in the wet lowland. The high prevalence in the dry lowland agro-ecology is mainly attributed to lack of easy access to health facilitates (as reported by $76 \%$ of the respondents) coupled with mounting temperature and untimely rain (reported by $65 \%$ of the respondents), which creates conducive environment for the hatching of the malaria vector.

Lack of access to health facilities is also aligned to vulnerability by the fact that about $44 \%$ of the respondents in the dry lowland agro-ecology reported family members missed either work or school in the past one year due to illness and lack of timely treatment. The corresponding proportion for the wet lowland agro-ecology is by far less (18\%) revealing that households in this agro-ecology are comparatively less vulnerable owing to better access to health facilities.

Better access to veterinary services is hypothesized to reduce the risk associated with livestock disease outbreak and hence reduces the vulnerability of smallholder farmers. In this regard, households in the wet lowland agro-ecology are relatively better off in terms of access to veterinary services as it takes only an hour to reach the nearest veterinary service point compared to 2.5 hours in the dry lowland. In terms of market access, households in the dry lowland agro-ecology are expected to travel for about three hours to reach nearest market compared to 1.5 hours for the wet lowland, which again signifies higher vulnerability in the dry lowland.

Generally, inadequate access to infrastructural services induces vulnerability of smallholder farmers to climate risks and in effect it induced low agricultural production and less adaptive capacity. When the three indictors in the infrastructure component are combined, the dry lowland -agro-ecology has lower adaptive capacity with an index of 0.183 compared to the wet lowland with an index of 0.286 (Table 5).

5) Socio Demographic profile

This major component consists of three indicators that include adult equivalent, 
dependency ratio and farm experience. In terms of adult equivalent ratio, a household in the wet lowland agro-ecology has an average of 3.04 compared to the dry lowland which is 2.96 and the difference is statistically significant $(t<$ 0.01 ). Higher adult equivalent imply larger labor endowment at the disposal of a farm household to accomplish various agricultural activities during peak season signifying the role of demographic variables for climate change adaptation as also inferred by [15] [25]. At the same time labor endowment is an important source of social capital in rural economies, signifying the potential that a farm household has for labor exchange and labor contribution in case of communal activities.

However, large family size may also stress household's adaptive capacity in the form of disguised unemployment particularly when the available livelihood options are very limited and unable to engage all members of the family in a productive activity. Consequently, large family size may contribute to households' vulnerability to climate change induced risks in the case of limited livelihood options and lower land to labor ratio. Therefore, the role of large family size for adaptation to climate risks is feasible where labor to land ratio is lower or where there is an opportunity to engage the family members in diversified livelihood options. In terms of dependency ratio, it is higher in the wet lowland agro-ecology (2.07) compared to the dry lowland (1.47) with a significant statistical difference $(t<0.001)$ and this may impose strain on available resources thereby reducing resilience to climate change and variability.

Farming experience is the other indicator used in the socio-demographic major component. It is expected that experience provides the opportunity to moderate vulnerability to climate change impacts through adjustments in terms of planting dates, choosing crop types/varieties, and applying farm management practices [12] [22]. In this regard, household heads in the wet lowland agro-ecology have longer farming experience (22.68 years) than those in the dry lowland agro-ecology (14.71 years) with a significant statistical difference $(t<$ 0.001). Therefore, farm households in the wet lowland agro-ecology have better chance of making possible adjustments to anticipated impacts of climate change/ variability.

Generally, the indicators used in the socio-demographic component have the potential to influence farmers' decision to adjust agricultural practices in response to climate change as also implied in the findings of [12] [26] [27]. Considering the three indicators that constitute the socio-demographic component, the dry lowland agro-ecology revealed lower adaptive capacity index (0.223) compared to 0.234 for the wet lowland (Table 5).

\section{6) Knowledge/skill component}

Education and training have a potential to influence farmers' decision and favorably contribute to climate change adaptation. In the wet lowland agro-ecology, about 38 percent of the respondents had access to different training opportunities in relation to climate related issues, while the corresponding proportion for the dry lowland agro-ecology is 21 percent. In terms of literacy level, about 42 
percent of the respondents in the wet lowland agro-ecology have formal education compared to 29 percent in the dry lowland. Considering the two indicators that constitute the knowledge/skill component, the dry lowland agro-ecology is more vulnerable with a low adaptive capacity score of 0.194 compared to the wet lowland with a score of 0.278 (Table 5).

\section{7) Social network and external support}

Variation is prevalent between the two agro-ecologies in terms of some social network profile indicators such as borrowing/lending and receiving/giving ratios. However, for other social network indicators the difference between the two agro-ecologies is not statistically significant and hence omitted for brevity. The wet lowland agro-ecology revealed a higher borrowing: lending ratio; as well as a higher receiving: giving ratio showing that households in this agro-ecology borrow and receive (in support) more from family and friends relative to the number of times they lent money or provided assistance in the past. Based on [18], households that borrow/receive money more than they lend/give are more vulnerable. But considering only these ratios without taking in to account receiving assistance from government/NGOs may overstate the vulnerability of household in the wet lowland agro-ecology while understating the same in the dry lowland agro-ecology. This is because; the number of times (in a year) that households in the dry lowland agro-ecology receive assistance through other channels is considerably high (44\%) while it is only $6 \%$ in the wet lowland agro-ecology.

Considering the external indicator in generating the index for the social network component, the adaptive capacity index is lower for the dry lowland agro-ecology (0.203) compared to the wet lowland (0.272) showing that households in the dry lowland agro-ecology are more vulnerable. Therefore, given the seven major components and the corresponding indicators, the adaptive capacity assessment reveals lower score for the dry low land agro-ecology $(0.201)$ compared to 0.255 for the wet lowland (Table 5).

\subsubsection{Livelihood Vulnerability Index Policy Implications}

The LVI-IPCC contributing factors, the major components and the sub-components are combined together on the basis of balanced weighted average approach following [15] [18] [21] to construct the LVI, where each sub-component contributes equally to the overall index although each major component is comprised of different number of sub-components. The calculated LVI and LVI-IPCC indices are in line with the pattern provided in focus groups discussion, key informant interviews, household survey and secondary data in reference to trends of exposure, sensitivity and vulnerability to climate related risks in the two agro-ecologies. This implies that LVI and LVI-IPCC could arguably capture main features of the study population in terms of exposure, sensitivity and adaptive capacity.

The 12 major components that yield the LVI scores are elements of either of the five capital forms (natural, human, social, financial and fiscal) and are grouped into the contributing factors namely exposure, sensitivity and adaptation capacity 
in order to compute the LVI-IPCC. Exposure is made up of the score of three major components; sensitivity is composed of two major components; while adaptive capacity is made up of aggregated scores of seven major components. The LVI-IPCC is on a scale from -1 (least vulnerable) to 1 (most vulnerable) and it is evident from the LVI-IPCC index that high values of exposure relative to adaptive capacity yield positive vulnerability scores while low values of exposure relative to adaptive capacity yield negative vulnerability scores. The sensitivity factor plays a role of a multiplier in such a way that high sensitivity leads to higher/lower LVI-IPCC score depending on the relative magnitude of exposure to adaptive capacity.

In the LVI assessment, use of sub-components/indicators and indices somehow helped to simplify a complex reality. However, directionality of indicators is arguable and context specific. For instance, in this study, large family size (converted to adult equivalent ratio) implied increased adaptive capacity or reduced vulnerability to climate impacts; however a different result may arise in a different context or location. Considering similar components and indicators in both agro-ecologies, the calculated LVI values confirmed that the two agro-ecologies are different in terms of vulnerability level where the dry lowland agro-ecology is more vulnerable than the wet lowland with comparatively higher exposure and sensitivity scores and lower adaptive capacity score.

Table 6 portrays the scores for the LVI-IPCC contributing factors indicating that the dry lowland agro-ecology has higher exposure with a score of 0.291

Table 6. Indexd major compeonts, LVI-IPCC contributig factors and the overall LVI-IPCC.

\begin{tabular}{ccccccc}
\hline Indexed major compnts by agro-ecology & $\begin{array}{c}\text { LVI-IPCC } \\
\text { contributing factors }\end{array}$ & Wet LL & Dry LL & Average \\
\hline Major components & Wet LL & Dry LL & & & & \\
Natural resource & 0.152 & 0.219 & Exposure & 0.239 & 0.291 & 0.265 \\
Natural disaster & 0.186 & 0.324 & & & & \\
CC change/variability & 0.379 & 0.331 & & & & \\
Land use/sustainability & 0.328 & 0.366 & Sensitivity & 0.221 & 0.293 & 0.257 \\
Agriculture & 0.152 & 0.244 & & & & \\
Income/wealth & 0.187 & 0.146 & & & & \\
Technology & 0.448 & 0.342 & & & & \\
Infrastructure & 0.286 & 0.183 & & & & \\
Knowledge/skill & 0.278 & 0.194 & Adaptive capcity & 0.255 & 0.201 & 0.228 \\
Livelihood & 0.134 & 0.145 & & & & \\
Socio-demographic & 0.234 & 0.223 & & & & \\
Social network/support & 0.272 & 0.203 & & & & \\
LVI-IPCC = [Exposure-Adaptive capacity] $\times$ Sensitivity & & & & \\
\hline
\end{tabular}


compared to the wet lowland which exhibited a score of 0.239 . Similarly, the dry lowland agro-ecology is lower in terms of adaptive capacity with a score of 0.201 compared to 0.255 for the wet lowland. Besides, the dry lowland agro-ecology is more sensitive to climate change and variability impacts (with a score of 0.293 ) than the wet lowland agro-ecology (with a score of 0.221). This shows that exposure exceeds adaptive capacity in the dry lowland agro-ecology and resulted in a positive LVI-IPCC score (0.026) which positioned this agro-ecologies in more vulnerable level than the wet lowland which unveil LVI-IPCC score of -0.004 . However, since the LVI-IPCC scores for the wet lowland agro-ecology $(-0.004)$ is very closer to the midpoint $(0)$ of the extreme vulnerability scales $(+1 \&-1)$, this agro-ecologies is positioned in a moderate vulnerability category.

The vulnerability scores of the 12 major components are also summarized in spider diagram (Figure 2), which ranges between 0 and 0.5 . The diagram revealed that the dry lowland agro-ecology is more vulnerable in 10 of the 12 (92\%) major components except for climate change/variability and livelihood major components. This causes the dry lowland agro-ecology to be more exposed and sensitive to climate change and variability impacts with lower adaptive capacity as compared to the wet lowland agro-ecology.

In terms of contribution of major components to the overall vulnerability score, natural disaster and climate variables (precipitation and temperature) components are the primary and secondary determinates of exposure in both agro-ecologies. Among the two major components included in the sensitivity factor, land use system/sustainability is found to be the primary determinant of sensitivity to climate change risks in both agro-ecologies. Similarly, major components that include technology, infrastructure, and knowledge/skill are fond to be important in determining adaptive capacity in both agro-ecologies in that order of importance.

The vulnerability triangle (Figure 3 ) portrays that the dry lowland agro-ecology is more exposed, more sensitive and exhibit a comparatively lower adaptive capacity to climate change and variability impacts compared to the wet lowland agro-ecology.

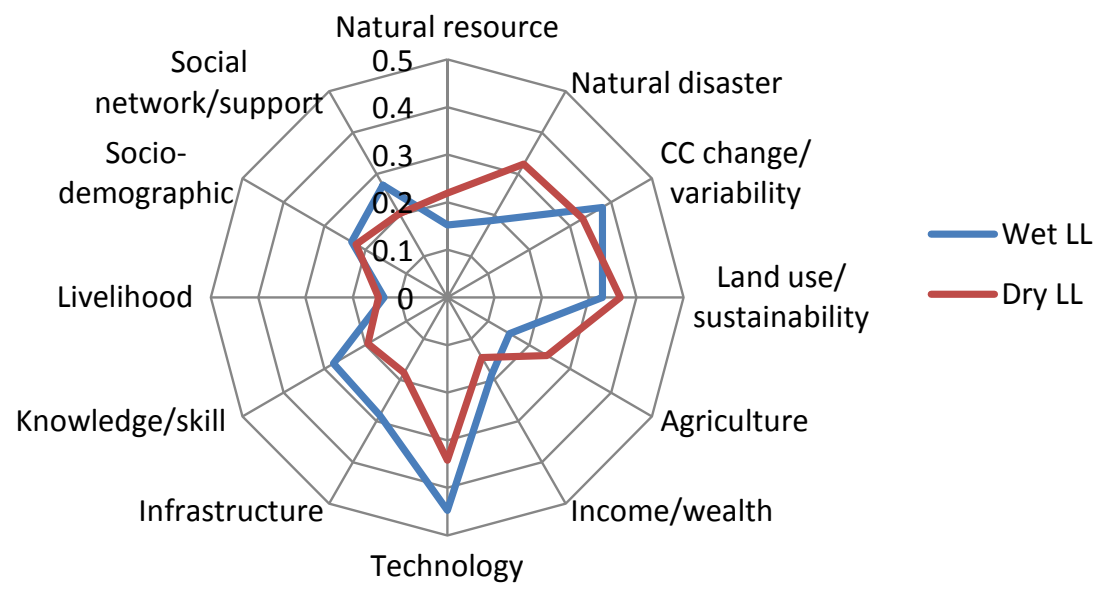

Figure 2. Vulnerability diagram of the major components for the two agro-ecologies. 


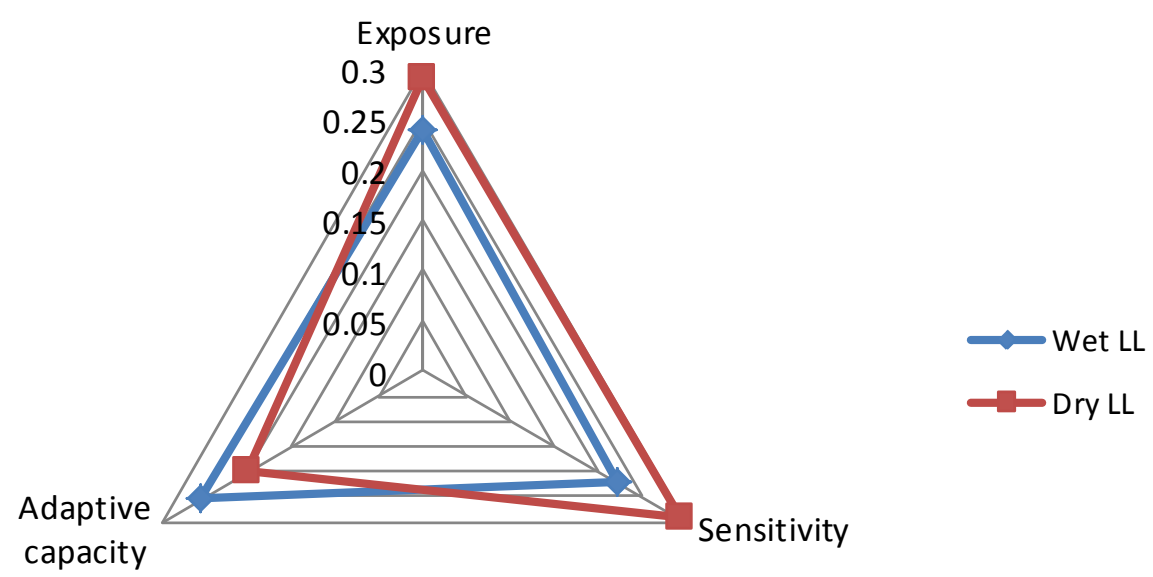

Figure 3. Vulnerability triangle of LVI-IPCC contributing factors.

\section{Conclusions and Recommendation}

Vulnerability analysis is an essential step towards designing effective adaptation that takes into perceived exposure, sensitivity and adaptive capacity. Particularly, agro-ecology specific vulnerability analysis captures spatial variation in vulnerability profiles and hence helps to systematically design context specific adaptation strategies. The present study used the LVI-IPCC framework to assess agro-ecology specific vulnerability to climate change/variability impacts at household level in the Dabus sub-basin of the Blue Nile River. The study area is characterized by diverse environmental, social, demographic and economic factors and hence the LVI-IPCC is aggregated at agro-ecology level to captures the diversity in the sub-basin.

The result shows that the dry lowland agro-ecology has a relatively higher exposure and sensitivity to climate stresses with a comparatively limited adaptive capacity as compared to the wet lowland agro-ecology. On the other hand the wet lowland agro-ecology exhibits intermediate vulnerability with a relatively lower perceived exposure and higher adaptive capacity. Higher exposure relative to adaptive capacity resulted in a positive LVI-IPCC score and this positioned the dry lowland agro-ecology in more vulnerable level than the wet lowland. Conversely, a higher adaptive capacity score relative to exposure unveils a negative LVI-IPCC score for the wet lowland agro-ecology and positioned it in a moderate vulnerability category.

The LVI-IPCC framework analysis also revealed the barriers that must be targeted to reduce exposure and sensitivity of smallholder farmers to climate risks and to enhance their adaptive capacity thereof. Accordingly, the result indicated the prominent factors that induce exposure and sensitivity to climate risks as well as the barriers that stress adaptive capacity in the two agro-ecologies. In this regard, natural disaster and climate variables are found to be major factors that induce exposure to climate risks in both agro-ecologies. On the other hand, lack of sustainable land use system influences sensitivity of smallholder farmers to climate risks in both agro-ecologies of the study area. The result also reveals the 
importance of agricultural technologies; access to infrastructure; and knowledge and skill in determining adaptive capacity in both agro-ecologies.

The findings of the study have important policy relevance that aimed at enhancing smallholder farmers' adaptive capacity to climate change and variability. The indices developed through this vulnerability assessment are useful to set location specific priorities for intervention that is most needed to cope up with the effects of climate variability and change. Accordingly, both agro-ecologies should be given attention in terms of climate specific extension/training opportunities and agricultural input dissemination. Climate risk exposure levels can be reduced through timely provision of climate specific information aimed at enhancing preparedness of farm households to extreme events. It is also crucial to expand availability of infrastructural facilities such as market, health services, and veterinary services so as to enhance adaptive capacity.

Therefore, the specific interventions that may call policy attention include supporting alternative livelihood options based on available resources (such as crafts from bamboo, gold mining), water harvesting for supplementary irrigation, and early warning system mechanism on extreme events. Parallel to this, improving the literacy level of smallholder farmers through informal education programs based on experience from other parts of Ethiopia is essential in this regard.

Finally, since the present analysis is at agro-ecology level, it can only provide an indicative vulnerability and hence more detail agro-ecosystem specific vulnerability information can be generated through further research in the study area. In the LVI assessment, use of sub-indicators and indices somehow helped to simplify a complex reality. Nevertheless, directionality of most of the indicators used in any LVI assessment is context specific and arguable. Indicators that revealed increased adaptive capacity or reduced vulnerability to climate impacts in a given context may show a different result in a different context or location.

\section{Acknowledgements}

The authors would like to thank Addis Ababa University (AAU) and Dire-Dawa University (DDU) for providing financial support for data collection and wire-up of this study. We would also like to thank the farmers, agricultural development agents, and local administrators of the study area for their assistance during the field work. We are also grateful to Addis Ababa University (AAU) for providing the required facilities during data analysis and write-up of this paper.

\section{References}

[1] IPCC (2007) Climate Change: Impacts, Adaptation, and Vulnerability. In: Contribution of Working Group II to the Fourth Assessment Report, Chap. 9, Cambridge University Press, Cambridge, UK.

[2] Collins, M., Knutti, R., Arblaster, J., Dufresne, J.-L., Fichefet, T., Friedlingstein, P., et al. (2013) Long-Term Climate Change: Projections, Commitments and Irreversibility. In: Stocker, T.F., et al., Eds., Climate Change 2013: Working Group I to the 
Fifth Assessment Report of the IPCC, Cambridge University Press, Cambridge, 1029-1136.

[3] Kirtman, B., Power, S.B., Adedoyin, J.A., Boer, G.J., Bojariu, R., Camilloni, I., et al., Eds. (2013) Near-Term Climate Change: Projections and Predictability. In: Stocker, T.F., et al., Eds., Climate Change 2013: Working Group I to the Fifth Assessment Report of the IPCC, Cambridge University Press, Cambridge, UK and New York, USA.:

[4] Adger, W.N. (2007) Vulnerability of Global Environmental Change 16 (3): 268-281. Agriculture: Ricardian Approach. World Bank Policy Research Paper No. 4342.

[5] Lobell, D.B., Bänziger, M., Magorokosho, C. and Vivek, B. (2011) Nonlinear Heat Effects on African Maize as Evidenced by Historical Yield Trials. Nature Climate Change, 1, 42-45. https://doi.org/10.1038/nclimate1043

[6] Conway, D. and Schipper, E.L.F. (2011) Adaptation to Climate Change in Africa: Challenges and Opportunities Identified from Ethiopia. Global Environmental Change, 21, 227-237. https://doi.org/10.1016/j.gloenvcha.2010.07.013

[7] Cooper, P.J.M., Dimes, J., Rao, K.P.C., Shapiro, B., Shiferaw, B. and Twomlow, S. (2008) Coping Better with Current Climatic Variability in the Rain-Fed Farming Systems of Sub-Saharan Africa: An Essential First Step in Adapting to Future Climate Change? Agriculture, Ecosystems \& Environment, 126, 24-35.

https://doi.org/10.1016/j.agee.2008.01.007

[8] Thomas, D.S.G., Twyman, C., Osbahr, H. and Hewitson, B. (2007) Adaptation to Climate Change and Variability: Farmer Responses to Intra-Seasonal Precipitation Trends in South Africa. Climatic Change, 83, 301-322. https://doi.org/10.1007/s10584-006-9205-4

[9] Von Braun, J. (2007) World Food Situation: New Driving Forces and Required Actions. International Food Policy Research Institute, Washington DC.

[10] World Bank (2010) Economics of Adaptation to Climate Change: Ethiopia. World Bank, Washington DC. https://openknowledge.worldbank.org/handle/10986/12504

[11] EPA (2011) Ethiopia's Climate-Resilient Green Economy (CRGE). Federal Democratic Republic of Ethiopia, Addis Ababa, Ethiopia.

[12] Asrat, P. and Simane, B. (2017) Adaptation Benefits of Climate-Smart Agricultural Practices in the Blue Nile Basin: Empirical Evidence from North-West Ethiopia. In: Filho, W.L., Munishi, P., Ogugu, N. and Simane, B., Eds., Climate Change Adaptation in Africa. Climate Change Management, Vol. 1, Springer, Cham, 45-59. https://doi.org/10.1007/978-3-319-49520-0_4

[13] Patt, A., Klein, R.J. and de la Vega-Leinert, A. (2009) Taking the Uncertainty in Climate Change Vulnerability Assessment Seriously. Comptes Rendus Geoscience, 337, 411-424. https://doi.org/10.1016/j.crte.2004.11.006

[14] Deressa, T.T., Hassan, R.M., Ringler, C., Alemu, T. and Yesuf, M. (2009) Determinants of Farmers' Choice of Adaptation Methods to Climate Change in the Nile Basin of Ethiopia. Global Environmental Change, 19, 248-255. https://doi.org/10.1016/j.gloenvcha.2009.01.002

[15] Simane B., Zaitchik B.F. and Foltz, J.D. (2016) Agro Ecosystem Specific Climate Vulnerability Analysis: Application of the Livelihood Vulnerability Index to a Tropical Highland Region. Mitigation and Adaptation Strategies for Global Change, 21, 39-65.

[16] Ribot J.C. (2009) Vulnerability Does Not Just Fall from the Sky: Towards Multi-Scale Pro Poor Climate Policy. In: Mearns, R. and Norton, A., Eds., Social Dimensions of Climate Change: Equity and Vulnerability in a Warming World, World 
Bank, Washington DC.

[17] Turner, L.B., Kasperson, R.E., Matson, P.A., McCarthy, J.J., Corell, R.W., Christensen, L., Eckley, N., Kasperson, J.X., Luers, A., Martello, M.L., Polsky, C., Pulsipher, A. and Schiller, A. (2003) A Framework for Vulnerability Analysis in Sustainability Science. Proceedings of the National Academy of Sciences of the United States of America, 100, 8074-8079. https://doi.org/10.1073/pnas.1231335100

[18] Hahn, M.B., Riederer, A.M. and Foster, S.O. (2009) The Livelihood Vulnerability Index: A Pragmatic Approach to Assessing Risks from Climate Variability and Change-A Case Study in Mozambique. Global Environmental Change, 19, 74-88. https://doi.org/10.1016/j.gloenvcha.2008.11.002

[19] Gbetibouo, A.G. and Ringler, C. (2009) Mapping South African Farming Sector Vulnerability to Climate Change and Variability: A Subnational Assessment. IFPRI Discussion Paper No. 00885, International Food Policy Research Institute, Washington DC, $43 \mathrm{p}$.

[20] United Nations Development Program (UNDP) (2007) Human Development Reports.

http://hdr.undp.org/sites/default/files/reports/268/hdr_20072008_en_complete.pdf

[21] Sullivan, C., Meigh, J.R. and Fediw, T.S. (2002) Derivation and Testing of the Water Poverty Index, Phase 1. Final Report, Department for International Development, U.

[22] Gutu, T., Bezabih, E. and Mengistu, K. (2012) Analysis of Vulnerability and Resilience to Climate Change Induced Shocks in North Shewa. Ethiopia. Journal of Agricultural Science, 3, 871-888.

[23] Fussel, H. (2010) How Inequitable Is the Global Distribution of Responsibility, Capability, and Vulnerability to Climate Change: A Comprehensive Indicator-Based Assessment. Global Environmental Change, 20, 597-611.

[24] Central Statistical Agency (CSA) (2012) Agricultural Sample Survey 2011/2012, Volume IV: Report on Land Utilization. Central Statistical Agency, Addis Ababa, Ethiopia.

[25] Deressa, T.T., Hassan, R.M. and Ringler, C. (2011) Perception of and Adaptation to Climate Change by Farmers in the Nile Basin of Ethiopia. Journal of Agricultural Science, 149, 23-31. https://doi.org/10.1017/S0021859610000687

[26] Nhemachena, C. and Hassan, R. (2007) Micro-Level Analysis of Farmers' Adaptation to Climate Change in Southern Africa. IFPRI Discussion Paper No. 00714, International Food Policy Research Institute, Washington DC.

[27] Maddison, D. (2007) The Perception of and Adaptation to Climate Change in Africa, CEEPA. Discussion Paper No. 10, Center for Environmental Economics and Policy in Africa, University of Pretoria, Pretoria, South Africa. 